\title{
EDITORIAL \\ The relevance of the BRAT and the management of ruptured brain aneurysms
}

\author{
Howard A. Riina, MD, ${ }^{1}$ and Fred G. Barker II, MD² \\ 'Departments of Neurosurgery, Neurology, and Radiology, New York University, New York, New York; and 2Department of \\ Neurosurgery, Massachusetts General Hospital, Boston, Massachusetts
}

$\mathrm{T}$ HE authors present the 10-year results of the Barrow Ruptured Aneurysm Trial (BRAT) for saccular aneurysms. ${ }^{5}$ Previous publications from the BRAT study, which compared the safety and efficacy of clipping versus coiling in patients presenting with subarachnoid hemorrhage, have included patient outcomes 1,3 , and 6 years after treatment. ${ }^{4,6,7}$ The present publication is limited to the saccular aneurysms from the trial.

The experience of the authors in the management of cerebral aneurysms is well known, and they should be commended for designing and following through with the BRAT study, in which 362 patients were initially randomized into either clipping or endovascular coiling cohorts (181 in each). Although there was no difference in poor outcome (modified Rankin Scale score $>2$ ) between the 2 groups at the end of the study, significantly more patients crossed over from the coiling assigned group to clipping than the reverse: 64 (36\%) coiling-assigned patients crossed over to clipping, compared to $<1 \%$ of clippingassigned patients who actually received coils. The same can be said for retreatment: $23 / 115(20 \%)$ in the coiling group underwent additional treatment, compared to $2 / 241$ $(0.8 \%)$ in those assigned to clipping. At the end of the 10year study period, 50/54 (93\%) of the clipped aneurysms with known aneurysm occlusion status were completely obliterated and only 5/23 (22\%) of the coiled aneurysms were. The authors conclude that "Rates of complete aneurysm obliteration and rates of retreatment favored patients who actually underwent clipping compared with those who underwent coiling." A limitation of these results is that relatively few patients among those alive at the end of the 10-year study period had known aneurysm obliteration status: 54 of 175 in the clipped cohort and 23 of 83 in the coiled cohort, or approximately $30 \%$ of each group. Whether the obliteration status of patients without verification was similar to this is unknown.
Another limitation of the BRAT study from a presentday vantage point is that detachable coils were used in isolation, without the more sophisticated endovascular occlusion strategies available today. Treatment of intracranial aneurysms with detachable coils began in the early 1990s with the introduction of the Guglielmi detachable coil. Technological strides have continued to propel endovascular treatment with techniques such as balloon remodeling and devices such as intracranial stents, flow diverters, intrasaccular devices, and most recently, devices designed specifically for aneurysms located at bifurcations. The BRAT study shows us a snapshot of time in endovascular treatment technology for aneurysms, one that is about 20 years old and does not include many more relevant treatment strategies that have considerably higher occlusion rates and that are associated with good outcomes. This limitation is unavoidable when studying a rapidly changing technology like endovascular aneurysm treatment, and surgical aneurysm treatment may also have changed in the last 20 years, with adoption at many centers of preoperative CT angiography to guide treatment choice and intraoperative fluorescence angiography to enhance safety as examples.

With the publication of 10-year follow-up of both the BRAT and the UK cohort of the International Subarachnoid Aneurysm Trial (ISAT-UK),, 2 one early prediction about the ISAT results can be reexamined. Early comment on ISAT raised the possibility that relatively lower aneurysm occlusion rates in the coiling cohort would, over time, translate into worse outcomes due to rebleeding and the morbidity of retreatment. Both BRAT and ISAT did show slightly higher rates of rebleeding in coil-treated patients, but the difference in absolute terms was slight. ${ }^{3,4,6,7}$ In ISAT-UK the difference in actuarial late rebleeding rates was approximately $1.5 \% 18$ years after treatment; in BRAT, 2 patients rebled after coiling and none rebled 
after surgery. Compared to the $24 \%$ of ISAT-UK patients known to have died by last follow-up, most commonly from cardiac disease or cancer, the specific mortality from rebleeding after coiling or clipping of ruptured aneurysms was low in both trials. Morbidity of retreatment in patients who underwent coiling was not reported in BRAT; in ISAT long-term changes in outcome after retreatment were rare.

Endovascular management of both ruptured and unruptured intracranial aneurysms has been an accepted management standard of care since 2003. The vast majority of aneurysm treatment outside the US is by endovascular means, and the most recent statistics suggest that endovascular treatment in the US is currently on the order of $60 \%-70 \%$.

The continued discussion of clipping versus coiling as sole treatment options is increasingly artificial, because no aneurysm (ruptured or unruptured) should be considered for treatment without bringing to bear all the tools that are currently available at a given center of excellence. Subtotal coiling of an aneurysm in the acute setting with subacute second-stage obliteration by adding a stent or flow diverter, or open surgery, is now common. Many clinicians will now consider stent and flow diverter-assisted coiling in the acute setting of subarachnoid hemorrhage. Fitting these techniques together with open surgical options to obtain optimal outcomes remains challenging today.

https://thejns.org/doi/abs/10.3171/2018.10.JNS182443

\section{References}

1. Molyneux AJ, Birks J, Clarke A, Sneade M, Kerr RS: The durability of endovascular coiling versus neurosurgical clipping of ruptured cerebral aneurysms: 18 year follow-up of the UK cohort of the International Subarachnoid Aneurysm Trial (ISAT). Lancet 385:691-697, 2015
2. Molyneux AJ, Kerr RS, Birks J, Ramzi N, Yarnold J, Sneade $\mathrm{M}$, et al: Risk of recurrent subarachnoid haemorrhage, death, or dependence and standardised mortality ratios after clipping or coiling of an intracranial aneurysm in the International Subarachnoid Aneurysm Trial (ISAT): long-term follow-up. Lancet Neurol 8:427-433, 2009

3. Molyneux AJ, Kerr RS, Yu LM, Clarke M, Sneade M, Yarnold JA, et al: International subarachnoid aneurysm trial (ISAT) of neurosurgical clipping versus endovascular coiling in 2143 patients with ruptured intracranial aneurysms: a randomised comparison of effects on survival, dependency, seizures, rebleeding, subgroups, and aneurysm occlusion. Lancet 366:809-817, 2005

4. Spetzler RF, McDougall CG, Albuquerque FC, Zabramski JM, Hills NK, Partovi S, et al: The Barrow Ruptured Aneurysm Trial: 3-year results. J Neurosurg 119:146-157, 2013

5. Spetzler RF, McDougall CG, Zabramski JM, Albuquerque FC, Hills NK, Nakaji P, et al: Ten-year analysis of saccular aneurysms in the Barrow Ruptured Aneurysm Trial. J Neurosurg [epub ahead of print March 8, 2019. DOI: 10.3171/2018.8.JNS181846]

6. Spetzler RF, McDougall CG, Zabramski JM, Albuquerque FC, Hills NK, Russin JJ, et al: The Barrow Ruptured Aneurysm Trial: 6-year results. J Neurosurg 123:609-617, 2015

7. Spetzler RF, Zabramski JM, McDougall CG, Albuquerque FC, Hills NK, Wallace RC, et al: Analysis of saccular aneurysms in the Barrow Ruptured Aneurysm Trial. J Neurosurg 128:120-125, 2018

\section{Disclosures}

The authors report no conflict of interest.

\section{Correspondence}

Howard A. Riina: howard.riina@nyulangone.org.

\section{INCLUDE WHEN CITING}

Published online March 8, 2019; DOI: 10.3171/2018.10.JNS182443. 